\title{
Socioeconomic deprivation, mortality and health of within-city migrants: a population cohort study
}

\author{
Ravi Maheswaran, ${ }^{1}$ Mark Strong, ${ }_{1}^{1}$ Phil Clifford, ${ }^{2}$ Louise Brewins ${ }^{3}$
}

${ }^{1}$ Public Health GIS Unit, School of Health and Related Research, University of Sheffield, Sheffield, UK

${ }^{2}$ North of England

Commissioning Support,

Sheffield, UK

${ }^{3}$ Sheffield City Council, Sheffield, UK

\section{Correspondence to} Professor Ravi Maheswaran, Public Health GIS Unit, School of Health and Related Research, University of Sheffield, Sheffield S1 4DA, UK; r.maheswaran@ sheffield.ac.uk

Received 24 October 2017 Revised 19 January 2018 Accepted 21 January 2018 Published Online First 6 February 2018
ABSTRACT

Background Evidence linking selective migration (the situation where people in good health move from deprived to affluent areas, whilst people in poor health move in the opposite direction) within local areas to mortality is inconclusive.

Methods Mortality in within-city migrants was examined using a Sheffield population cohort, adjusted for moves to care homes. The cohort comprised 310894 people aged 25+ years in 2001 followed up for 9.18 years, with 42252 (13.6\%) deaths. Information on preexisting medical conditions, socioeconomic indicators and smoking was available from a sample survey. Results Relative risks $(95 \% \mathrm{Cl})$ of mortality in migrants from deprived to affluent areas were lower compared with people remaining in deprived areas; 0.53 (0.42 to $0.65), 0.70$ (0.61 to 0.80$), 0.76$ (0.68 to 0.86$), 0.93$ (0.88 to 1.00$)$ and 0.98 (0.93 to 1.03 ) in the $25-44$, 45-64, 65-74, 75-84 and 85+ year age bands, respectively. They also had lower prevalence ORs (95\% $\mathrm{Cl})$ for bronchitis $(0.59(0.39$ to 0.89$))$, asthma (0.70 (0.53 to 0.93$))$, depression (0.59 (0.38 to 0.94$))$, and were less likely to receive benefits $(0.60(0.47$ to 0.76$))$ and less likely to smoke (0.66 (0.51 to 0.85$)$ ).

Conversely, mortality relative risks in migrants from affluent to deprived areas were higher compared with people remaining in affluent areas; 1.71 (1.37 to 2.12), 1.59 (1.40 to 1.82$), 1.44$ (1.26 to 1.63$), 1.18$ (1.10 to 1.27$)$ and 1.04 (1.00 to 1.09 ) in the corresponding age groups. They also had higher prevalence odds ratios for long-term illness (2.37 (1.71 to 3.29)), asthma (1.71 (1.25 to 2.35$))$, diabetes (3.03 (1.70 to 5.41$))$, depression (2.71 (1.74 to 4.21$))$, were more likely to receive benefits (2.25 (1.65 to 3.07$))$ and more likely to smoke (1.51 (1.12 to 2.05))

Conclusions People moving from deprived to affluent areas had lower mortality and better health, and vice versa, especially in the younger age groups. This study provides strong evidence linking selective migration within local areas to mortality.

\section{INTRODUCTION}

Geographical inequalities in health exist at many levels and are apparent even within cities. These inequalities can persist, despite efforts by governments to reduce inequalities through interventions in socioeconomically disadvantaged areas. One potential explanation for enduring inequalities is selective migration, that is, the situation where people with good health or with the socioeconomic determinants of good health move from more deprived to less deprived areas (which we refer to as 'deprived' and 'affluent' areas to make the text easier to follow), while people in poor health or with the socioeconomic determinants of poor health move in the opposite direction.

Within countries, and especially within cities, wider geopolitical factors are less diverse, allowing for a focused examination of selective migration at small spatial scales. A number of studies have examined health and its socioeconomic determinants in migrants within countries. While several reported that migrants moving into disadvantaged areas appeared to have poor health or determinants of poor health, ${ }^{1-10}$ others found no consistent patterns or appeared to find that migrants moving into areas of disadvantage had better health. ${ }^{11-13}$

The evidence regarding health of migrants moving in the opposite direction is less clear. Some studies have found that migrants moving to affluent areas had better health. ${ }^{3711-13}$ Others, however, found little evidence in support of this association. ${ }^{459}$ One even appeared to observe that migrants from deprived to affluent areas had worse health. ${ }^{2}$ The overall patterns appear inconsistent partly because interpretation is complicated by the different baseline groups used for comparison.

Only one of the above studies examined within-city migration. ${ }^{4}$ We previously investigated for evidence of selective migration in Sheffield, a city where stark gradients in deprivation and mortality have endured. ${ }^{14}$ We found some inconsistent patterns. While mortality among people moving from deprived to affluent areas was lower compared with people remaining in deprived areas in younger age groups, mortality appeared to be similar or paradoxically higher in older age groups. This apparent paradoxical pattern in older age groups has also been observed in other studies. ${ }^{137}$

A potential explanation for the apparent paradoxical pattern is moves to nursing and residential care homes. People who move to care homes are generally frail. ${ }^{15} 16$ The distorting effect of care homes on small-area level mortality rates is well recognised. ${ }^{1617}$ The effect could potentially also affect migration analyses, resulting in the paradoxical pattern observed if care homes are situated in affluent areas, or exaggerating the association between poor health and subsequent migration to deprived areas if these homes are situated in deprived areas.

In our previous work, care home locations were not linked to individuals and we were unable to adjust for potential distorting effects. ${ }^{14}$ In this paper, we present results of work where we linked data on location of care homes to the data set to correct for the care homes effect, and examined if mortality patterns associated with selective migration became 
clearer. Our focus in this paper is on the health of migrants at the individual level and not on the effects of migration on health at the area (population) level.

\section{METHODS}

\section{Study design and geography}

We used a population cohort study to examine the mortality patterns in within-city migrants in Sheffield. The city has a population of approximately 0.5 million and has a striking West-East gradient in socioeconomic deprivation, which is mirrored by a similar gradient in mortality. We used lower layer super output areas (LSOA) as our basic geographical units. LSOAs are standard census geographical areas created in the 2001 UK Census, with approximately 1500 people per LSOA. ${ }^{18}$ We used the Income Domain of the Index of Multiple Deprivation (IMD) from 2007 as our indicator of socioeconomic deprivation at the small-area level. ${ }^{19}$ The IMD is widely used by government agencies in England.

\section{Population and mortality data}

A pseudoanonymised data set was supplied by Sheffield Primary Care Trust (PCT), the health authority within the English National Health Service responsible for healthcare of Sheffield residents. The data set was derived from the general practice register, a continuously updated register of Sheffield residents registered with a general practitioner. The PCT kept regular 'snapshots' taken from the register and linked snapshots from October 2001 to January 2011 so that each record in the data set was for an individual. The data set contained the LSOA of residence for an individual at each snapshot time point if they were present in that snapshot. For patients who died, LSOA of residence at the time of death and year of death were provided. The data set included sex and year of birth. Deaths were obtained from October 2001 to December 2010.

\section{Nursing and residential care homes}

We did not have information at the individual level regarding residence in care homes. To correct for moves to care homes for older people, we first obtained data on care homes from Sheffield City Council. There were 88 care homes for older people (3798 beds) on the Council's care homes register in 2011. Postcodes of these care homes were linked to the population data set by the PCT, which supplied us with a flag indicating residents present in the January 2011 snapshot who had a care home postcode. For patients who died, the flag indicated if the postcode of residence at death was a care home postcode. We were only provided with flags, not postcodes, and at one time point only for each individual (ie, at the end of the follow-up period or at time of death) in order to preserve anonymity. Some ordinary residences shared postcodes with care homes so there was some misclassification inherent in this procedure.

\section{Statistical analysis}

We used two time points: (1) the cohort start point, and (2) an end point which was either the cohort end point for patients still alive or the year of death for patients who died during the follow-up period. We excluded people moving into or out of Sheffield during the follow-up period.

For people flagged as residing in a care home postcode at time of death or at the end of the study period, we looked back through their LSOAs for a change in LSOA which we took as the point at which they moved into a care home. We recoded all their LSOAs from this point on with their LSOA just prior to the move into a care home. People with a care home postcode but with no change in LSOA on looking back through their record were excluded from the cohort as the assumption was that they were in a care home from the start of the cohort study. We applied these changes only to people aged $65+$ years to limit the misclassification inherent in this procedure.

We classified LSOAs into two categories, 'affluent' or 'deprived', using the median IMD Income score. All people were classified into four categories: (1) resident in affluent areas at the start and end of the study period; (2) moving from affluent to deprived areas; (3) resident in deprived areas at the start and end of the study period; and (4) moving from deprived to affluent areas. We calculated (1) the relative risk of mortality (with $95 \%$ $\mathrm{CI}$ ) in people moving from deprived to affluent areas relative to those remaining in deprived areas, and (2) the relative risk of mortality in people moving from affluent to deprived areas relative to those remaining in affluent areas. The results are presented by age band at the start of the study, with the analysis restricted to people aged $25+$ years to exclude the majority of students within the city.

\section{Survey data}

Characteristics of a random sample of adults in Sheffield were available from the Second Sheffield Health and Illness Prevalence Survey (SHAIPS-2), ${ }^{20}$ a postal questionnaire survey carried out in 2000 , the year before the start of our cohort study. The survey only included people living in non-institutionalised accommodation. The response rate was 66\%, yielding 10185 completed questionnaires. The survey contained self-reported information on medical conditions (limiting long-term illness (LLTI), chronic bronchitis, asthma, angina, stroke, diabetes and depression), indicators of socioeconomic deprivation (access to cars, receipt of means-tested benefits) and smoking status. Details of the survey have been provided previously. ${ }^{14} 20$

\section{Analysis of survey data}

The migration-deprivation classification for survey respondents was extracted from the population cohort using a pseudoanonymised identifier. The analysis of health status was restricted to 8031 survey respondents aged $25+$ years remaining in Sheffield. Prevalence ORs were calculated for migrants from deprived to affluent areas relative to people remaining in deprived areas. Similarly, prevalence ORs were calculated for migrants from affluent to deprived areas relative to those remaining in affluent areas. Prevalence ORs $(95 \% \mathrm{CI})$ were adjusted for age and sex using logistic regression.

\section{RESULTS}

The total population in 2001 was 539737 , of whom 366440 were aged $25+$ years. Of these, 52715 (14.4\%) moved out of Sheffield. Of the remaining 313725, 2831 (0.9\%) were excluded because they were residents in a care home postcode throughout the study period (of whom 2732 (96.5\%) were aged $85+$ years and $2379(84 \%)$ died). This left the study cohort of 310894 people who were residents in Sheffield but not living in care homes for older people at the start of the study and who were either residents in Sheffield at the end of the follow-up period or had died in Sheffield. There were 42252 deaths in total, meaning that $13.6 \%$ died over the 9.18 -year follow-up period. Forty-five care homes (1906 beds) were situated in affluent areas and 43 (1892 beds) were in deprived areas.

Table 1 presents the population and mortality data for migrants from deprived to affluent areas compared with people 
Table 1 Relative risks of mortality in within-city migrants from deprived to affluent areas compared with people remaining in deprived areas. Sheffield, October 2001 to December 2010

\begin{tabular}{|c|c|c|c|}
\hline Characteristics & People remaining in deprived areas & $\begin{array}{l}\text { Migrants from deprived to affluent } \\
\text { areas }\end{array}$ & $\begin{array}{l}\text { Relative risk }(95 \% \mathrm{Cl}) \text { of mortality in migrants } \\
\text { versus non-migrants }\end{array}$ \\
\hline \multicolumn{4}{|l|}{$25-44$ years } \\
\hline Deaths (\%) & $972(1.76)$ & $89(0.93)$ & $0.53(0.42$ to 0.65$)$ \\
\hline Population & 55266 & 9615 & \\
\hline Mean age (SD) & $34.7(5.5)$ & $33.3(5.3)$ & \\
\hline Women (\%) & 47.6 & 45.5 & \\
\hline \multicolumn{4}{|l|}{ 45-64 years } \\
\hline Deaths (\%) & $4315(9.23)$ & $212(6.48)$ & $0.70(0.61$ to 0.80$)$ \\
\hline Population & 46771 & 3272 & \\
\hline Mean age (SD) & $54.4(5.7)$ & $53.5(5.7)$ & \\
\hline Women (\%) & 49.5 & 46.9 & \\
\hline \multicolumn{4}{|l|}{$65-74$ years } \\
\hline Deaths (\%) & $5900(29.87)$ & $215(22.75)$ & 0.76 (0.68 to 0.86$)$ \\
\hline Population & 19755 & 945 & \\
\hline Mean age (SD) & $69.4(2.9)$ & $69.3(2.8)$ & \\
\hline Women (\%) & 53.6 & 54.9 & \\
\hline \multicolumn{4}{|l|}{ 75-84 years } \\
\hline Deaths (\%) & $8753(59.5)$ & $426(55.61)$ & $0.93(0.88$ to 1.00$)$ \\
\hline Population & 14710 & 766 & \\
\hline Mean age (SD) & $78.9(2.7)$ & $79.1(2.7)$ & \\
\hline Women (\%) & 60.1 & 65.8 & \\
\hline \multicolumn{4}{|l|}{$\geq 85$ years } \\
\hline Deaths (\%) & 3712 (87.84) & $211(86.12)$ & $0.98(0.93$ to 1.03$)$ \\
\hline Population & 4226 & 245 & \\
\hline Mean age (SD) & $88.4(3.2)$ & $88.3(3.2)$ & \\
\hline Women (\%) & 73.0 & 80.4 & \\
\hline
\end{tabular}

remaining in deprived areas. In the $25-44$ years age group, these migrants had $47 \%(35 \%-58 \%)$ lower mortality than those remaining in deprived areas. Migrants in the 45-64 years age group had 30\% (20\%-39\%) lower mortality, those in the
65-74 years age group had 24\% (14\%-32\%) lower mortality and those in the 75-84 years age group had 7\% (0\%-12\%) lower mortality compared with people in the corresponding age groups remaining in deprived areas. There was little

Table 2 Characteristics and age and sex-adjusted prevalence ORs for SHAIPS-2 respondents before within-city migration from deprived to affluent areas compared with respondents remaining in deprived areas. Sheffield, 2000

\begin{tabular}{|c|c|c|c|}
\hline Characteristics & $\begin{array}{l}\text { People remaining in deprived areas } \\
\% \text { (Counts*) }\end{array}$ & $\begin{array}{l}\text { Migrants from deprived to affluent areas } \\
\% \text { (Counts*) }\end{array}$ & $\begin{array}{l}\text { Adjusted prevalence ORs }(95 \% \mathrm{Cl}) \text { for } \\
\text { migrants versus non-migrants }\end{array}$ \\
\hline \multicolumn{4}{|l|}{ Medical conditions } \\
\hline LLTI & $39.5(1328 / 3359)$ & $28.0(92 / 329)$ & 0.77 (0.59 to 1.01$)$ \\
\hline Bronchitis & $13.8(495 / 3584)$ & $7.8(27 / 344)$ & 0.59 (0.39 to 0.89$)$ \\
\hline Asthma & $26.3(941 / 3584)$ & $18.6(64 / 344)$ & 0.70 (0.53 to 0.93 ) \\
\hline Angina & $6.1(219 / 3584)$ & $3.8(13 / 344)$ & 0.72 (0.40 to 1.27$)$ \\
\hline Diabetes & $5.6(188 / 3347)$ & $4.0(13 / 327)$ & 0.88 (0.49 to 1.57 ) \\
\hline Depression & $10.4(371 / 3584)$ & $6.1(21 / 344)$ & 0.59 (0.38 to 0.94$)$ \\
\hline \multicolumn{4}{|l|}{ Socioeconomic deprivation } \\
\hline Access to fewer than two cars & $79.1(2682 / 3392)$ & $75.7(249 / 329)$ & $0.88(0.67$ to 1.15$)$ \\
\hline Receiving means-tested benefit & $44.8(1604 / 3584)$ & $31.4(108 / 344)$ & 0.60 (0.47 to 0.76$)$ \\
\hline
\end{tabular}

*With regard to denominator counts, answers based on straightforward questions (limiting long-term illness, stroke, diabetes, access to cars, smoking) had missing responses. For answers based on a more complex combination of responses (chronic bronchitis, asthma, angina, depression, means-tested benefits), where in order to have the condition, respondents needed to have responded positively to a number of questions, the assumption was that the remainder of the sample was negative for these conditions.

LLTI, limiting long-term illness; SHAIPS-2, Second Sheffield Health and Illness Prevalence Survey. 
Table 3 Relative risks of mortality in within-city migrants from affluent to deprived areas compared with people remaining in affluent areas. Sheffield, October 2001 to December 2010

\begin{tabular}{|c|c|c|c|}
\hline Characteristics & People remaining in affluent areas & $\begin{array}{l}\text { Migrants from affluent to deprived } \\
\text { areas }\end{array}$ & $\begin{array}{l}\text { Relative risk }(95 \% \mathrm{Cl}) \text { of mortality in migrants versus non- } \\
\text { migrants }\end{array}$ \\
\hline \multicolumn{4}{|l|}{$25-44$ years } \\
\hline Deaths (\%) & $473(0.85)$ & $96(1.45)$ & $1.71(1.37$ to 2.12$)$ \\
\hline Population & 55669 & 6620 & \\
\hline Mean age (SD) & $35.5(5.4)$ & $33.6(5.5)$ & \\
\hline Women (\%) & 49.9 & 44.9 & \\
\hline Deaths (\%) & $2826(5.16)$ & $213(8.22)$ & 1.59 (1.40 to 1.82$)$ \\
\hline Population & 54817 & 2591 & \\
\hline Mean age (SD) & $54.0(5.6)$ & $53.2(5.5)$ & \\
\hline Women (\%) & 50.3 & 44.8 & \\
\hline \multicolumn{4}{|l|}{$65-74$ years } \\
\hline \multicolumn{4}{|l|}{$75-84$ years } \\
\hline Deaths (\%) & $5993(50.89)$ & $289(60.08)$ & 1.18 (1.10 to 1.27$)$ \\
\hline Population & 11776 & 481 & \\
\hline Mean age (SD) & $78.9(2.7)$ & $79.3(2.8)$ & \\
\hline Women (\%) & 59.2 & 63.4 & \\
\hline \multicolumn{4}{|l|}{$\geq 85$ years } \\
\hline Deaths (\%) & $3402(86.17)$ & $225(90.00)$ & 1.04 (1.00 to 1.09$)$ \\
\hline Population & 3948 & 250 & \\
\hline Mean age (SD) & $88.6(3.2)$ & $88.4(2.9)$ & \\
\hline
\end{tabular}

difference in the $85+$ age group $(2 \%$ lower mortality $(-3 \%$ to $7 \%)$ ).

Table 2 shows the characteristics of people in the SHAIPS-2 survey who moved from deprived to affluent areas compared with those remaining in deprived areas. These migrants had lower age and sex-adjusted prevalence ORs for bronchitis $(0.59$ (95\% CI 0.39 to 0.89$)$ ), asthma (0.70 (95\% CI 0.53 to 0.93$)$ ) and depression $(0.59$ (95\% CI 0.38 to 0.94$)$ ). They were also less likely to be in receipt of means-tested benefits $(0.60$ (95\% CI 0.47 to 0.76$))$ and less likely to be current smokers (0.66 (95\% CI 0.51 to 0.85$)$ ).

Table 3 presents the population and mortality data for migrants from affluent to deprived areas compared with people remaining in affluent areas. In the 25-44 years age group, mortality in these migrants was $71 \%$ higher $(37 \%-112 \%)$ than those remaining in affluent areas. This excess mortality diminished with increasing age. The percentages were 59\% (40\%-82\%), 44\% (26\%-63\%), $18 \%(10 \%-27 \%)$ and $4 \%(0 \%-9 \%)$ in the $45-64,65-74,75-84$ and $85+$ year age groups, respectively.

Table 4 presents the characteristics of SHAIPS- 2 migrants from affluent to deprived areas compared with people remaining in affluent areas. These migrants had higher adjusted prevalence ORs for LLTI (2.37 (95\% CI 1.71 to 3.29)), asthma (1.71 (95\% CI 1.25 to 2.35$)$ ), diabetes (3.03 (95\% CI 1.70 to 5.41)) and depression (2.71 (95\% CI 1.74 to 4.21$)$ ). They were more likely to be current smokers (1.51 (95\% CI 1.12 to 2.05)). In addition, they had higher prevalence ORs for socioeconomic deprivation indicators; they were more likely to be receiving means-tested benefits $(2.25$ (95\%
CI 1.65 to 3.07)) and more likely to have access to fewer than two cars $(1.70$ (95\% CI 1.26 to 2.29$)$ ).

\section{DISCUSSION}

\section{Summary of main findings}

After adjusting for moves to care homes, we found clear evidence of selective migration. Within-city migrants from affluent to disadvantaged areas had higher mortality than people remaining in affluent areas. Conversely, mortality in within-city migrants from disadvantaged to affluent areas was lower than in people remaining in disadvantaged areas. Relative risks diminished with increasing age but remained clear with a consistent pattern across age groups. Patterns in the prevalence of medical conditions and determinants of health, ascertained before migration, were clearly consistent with the mortality patterns observed. Migrants moving to disadvantaged areas had poorer health than those remaining in affluent areas. Conversely, migrants moving to affluent areas had better health than those remaining in disadvantaged areas.

\section{Paradoxical effects and adjustment for moves to care homes}

An unpublished study by Sheffield PCT estimated that care home residents accounted for $23.7 \%$ of all deaths in Sheffield, indicating the scale of the potential for care homes to distort analyses examining selective migration. Table 5 shows the relative risks we found previously before correction for moves to care homes alongside the adjusted relative risks we found in this study. ${ }^{14}$ The care home correction removed the most striking 
Table 4 Characteristics and age and sex-adjusted prevalence ORs for SHAIPS-2 respondents before within-city migration from affluent to deprived areas compared with respondents remaining in affluent areas. Sheffield, 2000

\begin{tabular}{lccc}
\hline Characteristics & $\begin{array}{l}\text { People remaining in affluent areas } \\
\% \text { (Counts*) }\end{array}$ & $\begin{array}{l}\text { Migrants from affluent to deprived } \\
\text { areas } \\
\%(\text { Counts*) }\end{array}$ & $\begin{array}{l}\text { Adjusted prevalence ORs (95\% Cl) for } \\
\text { migrants versus non-migrants }\end{array}$ \\
\hline $\begin{array}{l}\text { Medical conditions } \\
\text { LLTI }\end{array}$ & $23.5(875 / 3716)$ & $33.2(80 / 241)$ & $2.37(1.71$ to 3.29$)$ \\
\hline $\begin{array}{l}\text { Bronchitis } \\
\text { Asthma }\end{array}$ & $6.9(265 / 3856)$ & $8.9(22 / 247)$ & $1.46(0.92$ to 2.31$)$ \\
\hline Angina & $15.0(578 / 3856)$ & $22.3(55 / 247)$ & $1.71(1.25$ to 2.35$)$ \\
\hline Stroke & $3.6(138 / 3856)$ & $4.9(12 / 247)$ & $1.56(0.84$ to 2.88$)$ \\
\hline Diabetes & $3.2(118 / 3705)$ & $5.2(12 / 232)$ & $3.03(1.70$ to 5.41$)$ \\
\hline Depression & $2.6(97 / 3681)$ & $6.5(15 / 230)$ & $2.71(1.74$ to 4.21$)$ \\
\hline Socioeconomic deprivation & $4.7(183 / 3856)$ & $10.9(27 / 247)$ & $1.70(1.26$ to 2.29$)$ \\
\hline Access to fewer than two cars & $63.9(2381 / 3729)$ & $71.3(169 / 237)$ & $2.25(1.65$ to 3.07$)$ \\
\hline Receiving means-tested benefit & $15.0(580 / 3856)$ & $25.9(64 / 247)$ & 1.51 (1.12 to 2.05$)$ \\
\hline Lifestyle factors & & $27.0(65 / 241)$ & \\
\hline Current smoker & $18.0(678 / 3763)$ & & \\
\hline
\end{tabular}

*With regard to denominator counts, answers based on straightforward questions (limiting long-term illness, stroke, diabetes, access to cars, smoking) had missing responses. For answers based on a more complex combination of responses (chronic bronchitis, asthma, angina, depression, means-tested benefits), where in order to have the condition, respondents needed to have responded positively to a number of questions, the assumption was that the remainder of the sample was negative for these conditions.

LLTI, limiting long-term illness; SHAIPS-2, Second Sheffield Health and Illness Prevalence Survey.

apparent anomaly we observed previously where mortality in the 75-84 years age group migrating from deprived to affluent areas was paradoxically higher relative to people remaining in deprived areas (relative risk 1.06 (95\% CI 1.01 to 1.10$)$ ). The corrected relative risk we observed here is 0.93 (95\% CI 0.88 to $1.00)$. In addition, the relative risk in the 67-74 years age band is now clearly below 1 , and the overall pattern is consistent. The correction for care homes has also marginally reduced the magnitude of the elevated relative risks in migrants from affluent to deprived areas in the 65-74 and 75-84 year age groups. This may be because moves of frail elderly people from affluent areas to care homes situated in deprived areas would have exaggerated the selective migration effect in this direction.

Table 5 Relative risks of mortality in within-city migrants before and after adjustment for moves to care homes. Sheffield, October 2001 to December 2010

\begin{tabular}{|c|c|c|}
\hline \multirow[b]{2}{*}{ Age band (years) } & \multicolumn{2}{|l|}{ Relative risk $(95 \% \mathrm{Cl})$} \\
\hline & $\begin{array}{l}\text { Before adjustment for } \\
\text { care homes }\end{array}$ & $\begin{array}{l}\text { After adjustment for } \\
\text { care homes }\end{array}$ \\
\hline \multicolumn{3}{|c|}{$\begin{array}{l}\text { Migrants moving from deprived to affluent areas compared with people remaining in } \\
\text { deprived areas }\end{array}$} \\
\hline $25-44$ & $0.53(0.42$ to 0.65$)$ & $0.53(0.42$ to 0.65$)$ \\
\hline $45-64$ & 0.75 (0.66 to 0.85$)$ & $0.70(0.61$ to 0.80$)$ \\
\hline $65-74$ & 0.97 (0.89 to 1.07$)$ & $0.76(0.68$ to 0.86$)$ \\
\hline $75-84$ & $1.06(1.01$ to 1.10$)$ & $0.93(0.88$ to 1.00$)$ \\
\hline $85+$ & $0.97(0.94$ to 1.01$)$ & $0.98(0.93$ to 1.03$)$ \\
\hline \multicolumn{3}{|c|}{$\begin{array}{l}\text { Migrants moving from affluent to deprived areas compared with people remaining in } \\
\text { affluent areas }\end{array}$} \\
\hline $25-44$ & 1.71 (1.37 to 2.12 ) & 1.71 (1.37 to 2.12 ) \\
\hline $45-64$ & $1.60(1.40$ to 1.83$)$ & 1.59 (1.40 to 1.82$)$ \\
\hline $65-74$ & 1.52 (1.36 to 1.70$)$ & $1.44(1.26$ to 1.63$)$ \\
\hline $75-84$ & 1.25 (1.19 to 1.32$)$ & 1.18 (1.10 to 1.27$)$ \\
\hline $85+$ & 1.01 (0.98 to 1.04$)$ & 1.04 (1.00 to 1.09$)$ \\
\hline
\end{tabular}

Three previous studies have reported apparently paradoxical results in the older age groups. ${ }^{137}$ Two were based on the Office for National Statistics Longitudinal Study, a 1\% representative sample of the population of England and Wales tracked through successive censuses and linked to mortality data. ${ }^{13}$ In one study, people living in communal establishments were excluded so moves to care homes would not have explained the paradoxical effect. ${ }^{1}$ The third study was based on residents in houses in the Netherlands so care homes would not have explained the paradoxical effect either. ${ }^{7}$ A potential explanation is frail elderly people moving to live closer to or with relatives in affluent areas. Deprivation-related health inequalities vary with age, being lowest around the age of 20 and highest around 50 before declining with increasing age. ${ }^{21-23}$ In addition, Norman and Boyle found that migration increased inequalities in the $30-50$ years age bracket. $^{23}$

\section{Comparison with previous studies on migrants to deprived areas}

Our study is the clearest yet on the strength of the mortality pattern in relation to age. Previous studies have reported that migrants to disadvantaged areas have poor health and determinants of poor health, consistent with our findings. ${ }^{1-10}$ However, some found no clear evidence of worse health among migrants to disadvantaged areas, or better health in these migrants. ${ }^{11-13}$ Migrants to disadvantaged areas in these studies included a relatively high proportion of healthy young adults, including those moving to higher education establishments situated in deprived areas. Two studies used areas based on local authority districts in Britain, which are substantially larger geographical units than LSOAs. $^{11} 12$

\section{Comparison with previous studies on migrants to affluent areas}

We found clear evidence of lower mortality and better health among migrants from deprived to affluent areas compared with people remaining in deprived areas. Some previous studies also 
found evidence of better health among migrants to affluent areas. $^{3}{ }^{711-13}$ Others, however, found no evidence of better health in migrants to affluent areas. ${ }^{459}$ However, two of these used either all non-migrants or migrants living in affluent areas as the baseline for comparison, so effects were harder to assess, and sample size was relatively small in the third which might have limited the power to detect differences. A further study appeared to find that migrants from disadvantaged to affluent areas had higher than expected mortality but there was no obvious explanation for this observation. ${ }^{2}$

\section{LIMITATIONS}

Our study strengths include the size of the population cohort, the use of very small geographical areas to assign area-level deprivation, linked mortality data and ascertainment of health status and socioeconomic determinants in a representative sample before migration occurred.

There are, however, a number of limitations. We did not have information at the individual level regarding residence in care homes. We therefore used care home postcodes as a proxy. This would have misclassified people living in houses sharing a postcode with a care home as care home residents. In addition, because of limitations with the available information on care homes, the analysis was based on the implicit assumption that care homes were in operation throughout the follow-up period. Where this assumption did not hold, there would have been further misclassification of care home status. It would have been preferable to have had information linked in at the individual level but routine systems were not in place to enable this linkage. The SHAIPS-2 survey was a self-completed questionnaire which could have contained inaccuracies in ascertainment of disease conditions and health determinants. The cohort was based on people registered with general practitioners and those not registered would not have been included in the analysis. Estimation of the level of non-registration is however problematic due to underenumeration in UK censuses. Comparisons with 2011 census data for England and Wales indicated that

\section{What is already known on this subject}

- Evidence linking selective migration and health has been sought in studies at international and within country levels but the results are not consistent. Very few studies have examined within-city migration, where wider geopolitical factors have less influence and evidence may be clearer.

\section{What this study adds}

- After adjusting for the potential distorting effect of care homes, there was clear and consistent evidence of selective within-city migration.

- People moving from deprived to affluent areas had lower mortality and better health than people remaining in deprived areas.

- People moving from affluent to deprived areas had higher mortality and worse health than people remaining in affluent areas.

- The patterns diminished with increasing age.

- This study provides strong evidence linking selective migration within local areas to mortality. general practice registered counts generally exceeded census counts between ages 20 and 65 years, especially for men, but varied by area and was within $3 \%$ for Sheffield. ${ }^{24}$ In addition, if people moved but did not inform their general practitioners, their recorded location would have been inaccurate. Misclassification could also have resulted from areas becoming more or less deprived over time. ${ }^{25}$ Despite these limitations, we observed clear and consistent patterns.

\section{CONCLUSIONS}

After adjusting for the potential distorting effect of care homes, we found strong evidence of selective within-city migration, with people moving from deprived to affluent areas having lower mortality and better health than people remaining in deprived areas. The converse was evident for people moving in the opposite direction. In terms of public health policy, our study indicates that within-city migration should be taken into account when planning and evaluating interventions, particularly longterm policy interventions which aim to reduce health inequalities at the area level.

Contributors RM designed the study in collaboration with LB and PC. PC assembled the database. RM analysed the data with input from MS and wrote the first draft. All authors contributed to the paper and approved the final draft.

Funding This work was supported by a grant from Sheffield Primary Care Trust.

Competing interests The authors report receiving a grant from Sheffield Primary Care Trust to conduct the study.

Ethics approval University of Sheffield Research Ethics Committee.

Provenance and peer review Not commissioned; externally peer reviewed.

(c) Article author(s) (or their employer(s) unless otherwise stated in the text of the article) 2018. All rights reserved. No commercial use is permitted unless otherwise expressly granted.

\section{REFERENCES}

1 Norman P, Boyle P, Rees P. Selective migration, health and deprivation: a longitudinal analysis. Soc Sci Med 2005;60:2755-71.

2 Connolly S, O'Reilly D. The contribution of migration to changes in the distribution of health over time: five-year follow-up study in Northern Ireland. Soc Sci Med 2007:65:1004-11.

3 Connolly S, O'Reilly D, Rosato M. Increasing inequalities in health: is it an artefact caused by the selective movement of people? Soc Sci Med 2007;64:2008-15.

4 van Lenthe FJ, Martikainen P, Mackenbach JP. Neighbourhood inequalities in health and health-related behaviour: results of selective migration? Health Place 2007;13:123-37

5 Martikainen P, Sipilä P, Blomgren J, et al. The effects of migration on the relationship between area socioeconomic structure and mortality. Health Place 2008;14:361-6

6 Brown D, O'Reilly D, Gayle V, et al. Socio-demographic and health characteristics of individuals left behind in deprived and declining areas in Scotland. Health Place 2012:18:440-4.

7 Jongeneel-Grimen B, Droomers M, Stronks K, et al. Migration and geographical inequalities in health in the Netherlands: an investigation of age patterns. Int J Public Health 2013;58:845-54.

8 Jokela M. Are neighborhood health associations causal? A 10-year prospective cohort study with repeated measurements. Am J Epidemiol 2014;180:776-84.

9 Tunstall $\mathrm{H}$, Mitchell R, Pearce J, et al. The general and mental health of movers to more- and less-disadvantaged socio-economic and physical environments within the UK. Soc Sci Med 2014;118:97-107.

10 Green MA, Subramanian SV, Vickers D, et al. Internal migration, area effects and health: Does where you move to impact upon your health? Soc Sci Med 2015;136137:27-34.

11 Brimblecombe N, Dorling D, Shaw M. Migration and geographical inequalities in health in Britain. Soc Sci Med 2000:50:861-78.

12 Riva M, Curtis S, Norman P. Residential mobility within England and urban-rural inequalities in mortality. Soc Sci Med 2011;73:1698-706.

13 Dijkstra A, Kibele EU, Verweij A, et al. Can selective migration explain why health is worse in regions with population decline?: A study on migration and self-rated health in the Netherlands. Eur J Public Health 2015;25:944-50. 
14 Maheswaran R, Pearson T, Strong M, et al. Assessing the impact of selective migration and care homes on geographical inequalities in health--a total population cohort study in Sheffield. Spat Spatiotemporal Epidemiol 2014;10:85-97.

15 Shah SM, Carey IM, Harris T, et al. Mortality in older care home residents in England and Wales. Age Ageing 2013;42:209-15.

16 Jonker MF, van Lenthe FJ, Donkers $B$, et al. The impact of nursing homes on small-area life expectancies. Health Place 2013;19:25-32.

17 Williams ES, Dinsdale $H$, Eayres D, et al. Impact of nursing home deaths on life expectancy calculations in small areas. J Epidemiol Community Health 2004;58:958-62.

18 Office for National Statistics. Census geography. https://www.ons.gov.uk/ methodology/geography/ukgeographies/censusgeography

19 Department for Communities and Local Government. English indices of deprivation. 2012 https://www.gov.uk/government/collections/english-indices-of-deprivation

20 Coy J, Skinner J, Stead M, et al. Report of the second Sheffield Health and IIIness Prevalence Survey (SHAIPS 2). Sheffield: Sheffield Health Authority, 2002.
21 Dibben C, Popham F. Are health inequalities evident at all ages? An ecological study of English mortality records. Eur J Public Health 2013;23:39-45.

22 Green MA. The equalisation hypothesis and changes in geographical inequalities of age based mortality in England, 2002-2004 to 2008-2010. Soc Sci Med 2013;87:93-8

23 Norman P, Boyle P. Are health inequalities between differently deprived areas evident at different ages? A longitudinal study of census records in England and Wales, 1991 2001. Health Place 2014:26:88-93.

24 Office for National Statistics. Beyond 2011: administrative data sources report: NHS patient register. 2012. http://webarchive.nationalarchives.gov.uk/20160113081938/ http://www.ons.gov.uk/ons/about-ons/who-ons-are/programmes-and-projects/ beyond-2011/reports-and-publications/sources-reports/beyond-2011-administrativedata-sources-report-nhs-patient-register-s1-.pdf

25 Norman P. The changing geography of deprivation in Britain, 1971 to 2011 and Beyond. In: Champion T, Falkingham J, eds. Population change in the United Kingdom. London: Rowman \& Littlefield, 2016:193-214. 